\title{
Morphologically similar but not closely related: the long-spored species of Subulicystidium (Trechisporales, Basidiomycota)
}

\author{
Alexander Ordynets ${ }^{1}$ (D) Robert Liebisch ${ }^{1} \cdot$ Ludmila Lysenko $^{1} \cdot$ David Scherf $^{1} \cdot$ Sergey Volobuev $^{2} \cdot$ Alessandro Saitta $^{3}$. \\ Karl-Henrik Larsson ${ }^{4} \cdot$ Eugene Yurchenko $^{5}$ • Bart Buyck ${ }^{6}$ Sergey Bolshakov ${ }^{2}$ • Ewald Langer ${ }^{1}$
}

Received: 26 March 2020 / Revised: 29 April 2020 / Accepted: 1 May 2020

(C) The Author(s) 2020

\begin{abstract}
Species boundaries and geographic distribution of corticioid fungi (resupinate Basidiomycota) are often poorly known. Our recent study on Subulicystidium showed that species diversity in this genus is at least twice as high as previously recognized. This re-estimation of the species diversity was based on a study of only a part of the genus. The present study sheds light on molecular and morphological diversity of three more species. We generated 27 ITS and 2428 S nuclear ribosomal DNA sequences from 49 specimens labelled as Subulicystidium cochleum, S. longisporum and S. perlongisporum and collected in distant geographic localities. We assessed pairwise dissimilarities and phylogenetic relationships of DNA sequences with Bayesian and maximum likelihood methods. We correlated phylogenetic information with morphological data on spores and cystidia. We found that the three species are not closely related, despite their similarity in spore shape and size. In one of the species, S. perlongisporum, we detected the presence of two sympatric lineages. These lineages are not morphologically distinct, except for a small difference in the mean length of cystidia. Our study provides a further example of transoceanic species distribution in Agaricomycetes.
\end{abstract}

Keywords Cryptic species · Genetic distance $\cdot$ Homoplasic character $\cdot$ Internal transcribed spacer $\cdot$ Large subunit $\cdot$ Traditional morphometrics

\section{Introduction}

Species boundaries and geographic distribution of corticioid fungi (resupinate Basidiomycota) are often poorly known. Fungi from the genus Subulicystidium Parmasto 1968 (Hydnodontaceae, Trechisporales, Agaricomycetes,

This article is part of the Topical Collection on Basidiomycote Mycology in honor of Franz Oberwinkler who passed away in March 2018.

Section Editor: Yu-Cheng Dai

Electronic supplementary material The online version of this article (https://doi.org/10.1007/s11557-020-01587-3) contains supplementary material, which is available to authorized users.

Alexander Ordynets

a.ordynets@uni-kassel.de

1 Department of Ecology, FB 10 Mathematics and Natural Sciences, University of Kassel, Heinrich-Plett-Strasse 40,

34132 Kassel, Germany

2 Laboratory of Systematics and Geography of Fungi, Komarov Botanical Institute of the Russian Academy of Sciences, Professora Popova str. 2, 197376 St. Petersburg, Russia
Basidiomycota) occur on moderately or strongly decayed wood and are common in many forest ecosystems, especially tropical ones. For many decades, Subulicystidium has challenged both morphology- and DNA-based mycology. The presence of numerous transitional forms as to basidiospore size and shape hindered species delimitation (Oberwinkler
3 Department of Agricultural, Food and Forest Sciences, University of Palermo, Viale delle Scienze ed. 4, 90128 Palermo, Italy

4 Natural History Museum, University of Oslo, P.O. Box 1172 Blindern, 0318 Oslo, Norway

5 Department of Biotechnology, Polessky State University, Dnyaprouskai flatylii str. 23, BY-225710 Pinsk, Belarus

6 Département Systématique et Évolution, Muséum National d'Histoire Naturelle, rue Buffon 12, F-75005 Paris, France 
1977; Liberta 1980; Duhem and Michel 2001). Recently, Ordynets et al. (2018) described 11 new species based on analyses of ribosomal DNA and morphometry of spores and cystidia. The genus now includes 22 accepted species (Index Fungorum 2019).

In Subulicystidium, morphological species identification through a key traditionally begins with defining whether the spores' length-to-width ratio $(Q)$ is lower or higher than four. This criterion is stable and allows one to assign each specimen unambiguously to one of the morphogroup (Boidin and Gilles 1988; Duhem and Michel 2001; Gorjón et al. 2012). For easier communication, Ordynets et al. (2018) labelled these morphogroups as "short-spored" $(Q<4)$ and "long-spored" $(Q>4)$. In that study, the authors focused exclusively on short-spored taxa. Liu et al. (2019) provided an insight into the diversity of the long-spored morphogroup by describing two new species from East Asia (Subulicystidium acerosum S.H. He \& S.L. Liu and S. tropicum S.H. He \& S.L. Liu).

The present study focuses on additional long-spored species, viz. Subulicystidium cochleum Punugu, S. longisporum (Pat.) Parmasto and S. perlongisporum Boidin \& Gilles. $S$. longisporum is the oldest described species and also the type of the genus. S. cochleum was claimed to differ from S. longisporum by the presence of needle-like crystals on cystidia and by more strongly curved spores (Punugu et al. 1980). S. perlongisporum was described by Boidin and Gilles (1988) and differs from $S$. longisporum by more elongated spores. The holotype of $S$. longisporum is from Tunisia (Patouillard 1894) and the type of S. perlongisporum is from La Réunion Island. Both species have been recorded from several continents as well as from islands in the Caribbean, Indian Ocean and the Pacific. The holotype of S. cochleum is from Saint Lucia Island in the Caribbean and outside that region was only reported from Hawaii (Martini 2020). Almost all records of these species are based on the observation of fruiting bodies and few DNA sequences are available.

In this study, we use molecular data to answer (1) whether S. cochleum, S. longisporum and S. perlongisporum can be considered as distinct and monophyletic species and (2) whether the similarity in spore shape and size is reflected by the phylogenetic position. For that, we explore the variation and relationship of DNA sequences of the nuclear ribosomal ITS and $28 \mathrm{~S}$ region from geographically scattered herbarium specimens. We also correlate molecular data with the measurements of basidiospores and cystidia.

\section{Materials and methods}

\section{Microscopy}

In this study, we examined 49 herbarium specimens: 37 identified as Subulicystidium perlongisporum, seven as
S. cochleum and five as $S$. longisporum. They are preserved in the following herbaria: ARAN, FR, GB, KAS, KR, MSK, LE, LY, MG, O, PC, SP, TU and TUB (acronyms, follow http://sweetgum.nybg.org/science/ih). Detailed information on the studied collections is provided in Supplementary file 1.

Sections from dried herbarium specimens were examined in $3 \%$ aqueous solution of potassium hydroxide $(\mathrm{KOH})$ mixed with $1 \%$ aqueous solution of Phloxine at $\times 1000$ magnification, using a Leica DM500 light microscope. Images were captured with a built-in ICC 50 HD Camera using Leica Application Suite EZ software versions 3.2.1 and 3.4.2 (Leica Microsystems GmbH, Wetzlar, Germany). Measurements were done with the software “Makroaufmaßprogramm” from Jens Rüdigs (Rüdig 2019, https://ruedig.de/tmp/messprogramm.htm) and processed with the software "Smaff" v. 3.2 (Wilk 2012).

Where possible at least 30 basidiospores per specimen were measured for all 36 sequenced specimens ( 28 specimens of $S$. perlongisporum, 5 of $S$. longisporum and 3 of S. cochleum). For each specimen, an automated search for size outliers, and their exclusion was performed as described in Ordynets et al. (2018). This resulted in 1203 measurements after excluding outliers (see Supplementary file 2). Spore sizes were divided into a 90\% main range, and 5\% lowest and highest values as described in Ordynets and Denecke (2018), by means of the package "dplyr" (Wickham et al. 2019) in R v. 3.5.3 (R Core Team 2019).

During the measurements of cystidia, the protruding bowtie crystals were included in the cystidium diameter. In most cases, between 9 and 28 cystidia per specimen were measured (in two cases nine and in one case 38). In total 645 cystidia were measured from 36 sequenced specimens (see Supplementary file 2). These measurements were not checked for outliers and were directly summarized on specimen level with the same method as used for the spores (Ordynets and Denecke 2018). To compare the mean size and shape of spores and cystidia between phylogenetically defined groups, the unpaired two-sample Wilcoxon test was used as implemented in the function "wilcox.test", with default settings, from the R "stats" package (R Core Team 2019).

\section{DNA extraction, amplification and sequencing}

Sequences of two nuclear ribosomal DNA regions were considered in our study: internal transcribed spacer (nc ITS rDNA) and ribosomal large subunit-coding DNA (nc 28S rDNA). Total DNA was extracted from dried herbarium specimens. For this, pieces of fungal fruiting bodies totalling about $20 \mathrm{~mm}^{2}$ were placed into 2-ml tubes containing two small and two large sterile metallic beads. The tube content was ground in the mixer mill for $1 \mathrm{~min}$ at $30 \mathrm{~Hz}$. Then, tubes were centrifuged at $16,060 \mathrm{~g}$ for $30 \mathrm{~s}$. The following methods of total DNA isolation were used: 
(1) Most of the specimens were processed with the E.Z.N.A. ${ }^{\circledR}$ Fungal DNA Mini Kit from Omega Biotek, Inc. (Norcross, GA, USA). We used the short version of the protocol from the manufacturer's manual with few modifications. In particular, after adding FG1 buffer, we added to each tube $10 \mu \mathrm{l}$ of proteinase $\mathrm{K}$ (20 mg/ml, Ambion, Thermo Fischer Scientific, Waltham, MA, USA) and used neither RNase A or $\beta$ mercaptoethanol. We also used a fixed volume of $300 \mu \mathrm{l}$ for FG3 buffer and $600 \mu \mathrm{l}$ for $100 \%$ ethanol. We added sterile deionized water instead of elution buffer at the two final elution steps. We performed all the centrifuging steps at $9500 \mathrm{~g}$. We used the DNA gained with this protocol in undiluted form for PCR.

(2) For Reunionese specimens collected in 2013 and 2015 (herbaria KAS, FR), the protocol of Izumitsu et al. (2012) was used (see details in Ordynets et al. 2018).

(3) For collections from Russia (herbarium LE), total DNA extraction followed the manufacturer's protocol of the NucleoSpin Plant II kit (Macherey-Nagel GmbH and Co. KG, Düren, Germany).

(4) In specimens from Sicily and Estonia (herbarium TU), the total DNA was extracted in a lysis buffer $(0.8 \mathrm{M}$ Tris$\mathrm{HCl}, 0.2 \mathrm{M}\left(\mathrm{NH}_{4}\right)_{2} \mathrm{SO}_{4}, 0.2 \% \mathrm{w} / \mathrm{v}$ Tween-20) (Soil BioDyne, Tartu, Estonia) using a proteinase $\mathrm{K}$ method (100 $\mu \mathrm{l}$ lysis buffer and $2.5 \mu \mathrm{l}$ proteinase $\mathrm{K}$; incubation at $56{ }^{\circ} \mathrm{C}$ for $24 \mathrm{~h}$ and at $98{ }^{\circ} \mathrm{C}$ for $15 \mathrm{~min}$ ).

Primer pairs used to amplify the complete ITS region were ITS1f/ITS4, ITS1/ITS4, ITS1f/ITS4B and ITS5/ITS4 (White et al. 1990; Gardes and Bruns 1993). If the amplification of the complete ITS region failed, it was performed for shorter ITS portions with primer pairs ITS1/ITS2 and ITS3/ITS4. Each of these two fragments represents nearly half of ITS and they were later assembled to a single complete ITS sequence. The D1-D2 domains at the $5^{\prime}$ end of the $28 \mathrm{~S}$ region were amplified with primer pair LR0R/LR5 (Hopple and Vilgalys 1999) or alternatively with NL1/NL4 (O’Donnell 1992). Finally, for some Sicilian collections, primer pair ITS1OF/LB-W was used to recover the full ITS and partial $28 \mathrm{~S}$ region with a total length of ca. 1000 nucleotides (Tedersoo et al. 2008).

The PCR after extraction methods 1 and 2 were performed on $25 \mu \mathrm{l}$ solution containing $2.5 \mu \mathrm{l}$ of extracted DNA and $22.5 \mu \mathrm{l}$ master mix. One master mix portion contained $15.1 \mu \mathrm{l}$ of double-distilled $\mathrm{H}_{2} \mathrm{O}, 5 \mu \mathrm{l}$ of $5 \times$ MangoTaq ${ }^{\mathrm{TM}}$ Colored Reaction Buffer, $1 \mu \mathrm{l}$ dNTPs $(5 \mathrm{mM}), 1 \mu \mathrm{lgCl}_{2}$ (50 mM), $0.1 \mu$ l MangoTaq DNA polymerase 5 units/ $\mu$ (all components above from Bioline $\mathrm{GmbH}$, Luckenwalde, Germany), $1 \mu \mathrm{l}$ of bovine serum albumin $(20 \mu \mathrm{g} / \mu \mathrm{l})$ and $0.4 \mu \mathrm{l}$ of each forward and reverse primers $(25 \mathrm{pmol})$ from Thermo Fisher Scientific (Waltham, MA, USA). PCR with primer pairs ITS1F/ITS4 and ITS3/ITS4 was set as initial denaturation at $94{ }^{\circ} \mathrm{C}$ for $3 \mathrm{~min}$ followed by 29 cycles of denaturation at $94{ }^{\circ} \mathrm{C}$ for $30 \mathrm{~s}$, annealing at $55{ }^{\circ} \mathrm{C}$ for $45 \mathrm{~s}$ and extension at $72{ }^{\circ} \mathrm{C}$ for $60 \mathrm{~s}$; final elongation was done at $72{ }^{\circ} \mathrm{C}$ for $7 \mathrm{~min}$. PCR with primer pair LR0R/LR5 differed in having the annealing temperature as $58{ }^{\circ} \mathrm{C}$ and for primer pairs NL1/NL4 and ITS1/ITS2 as $60{ }^{\circ} \mathrm{C}$. PCR products were checked on $1 \%$ agarose gel stained with GelRed fluorescence dye (Biotium, Hayward, CA, USA). PCR products were cleaned with QIAquick PCR Purification Kit according to the manufacturer's instructions (QIAGEN GmbH, Hilden, Germany). Sanger sequencing of purified products was performed by the company Eurofins Genomics Germany $\mathrm{GmbH}$ (Ebersberg, Germany) and in the facilities of the Senckenberg Research Institute and Natural History Museum (Frankfurt am Main, Germany). The primers used for sequencing were identical to those used for amplification.

The PCR after extraction method 3 was performed on $20 \mu \mathrm{l}$ solution containing $2 \mu$ l of extracted DNA, 7.6 $\mu$ l of distilled $\mathrm{H}_{2} \mathrm{O}$ and $10 \mu \mathrm{l}$ of iQ Supermix (Bio-Rad Laboratories, USA). The purification of PCR products was made with the GeneJET PCR Purification Kit (Thermo Fisher Scientific, Lithuania). Sequencing was performed in house on ABI 3130 Genetic Analyzer (Applied Biosystems, CA, USA).

The PCR after extraction method 4 was performed in $25 \mu \mathrm{l}$ containing $0.5 \mu \mathrm{l}$ of each primer, $5 \mu$ l FirePol Mastermix (Solis BioDyne, Tartu, Estonia), $1 \mu$ l of 10 times diluted DNA template and sterilized distilled water. PCR conditions for the amplification of ITS region were set as initial denaturation at $95^{\circ} \mathrm{C}$ for $15 \mathrm{~min}$ followed by 35 cycles of denaturation at $95^{\circ} \mathrm{C}$ for $30 \mathrm{~s}$, annealing at $55^{\circ} \mathrm{C}$ for $30 \mathrm{~s}$ and extension $72{ }^{\circ} \mathrm{C}$ for $60 \mathrm{~s}$; final elongation was done at $72{ }^{\circ} \mathrm{C}$ for $7 \mathrm{~min}$. PCR products were cleaned using Exo-SAP enzymes (GE Healthcare, Freiburg, Germany) using incubation at $37^{\circ} \mathrm{C}$ for $45 \mathrm{~min}$ and at $85^{\circ} \mathrm{C}$ for $15 \mathrm{~min}$. PCR products were sequenced by Macrogen Inc. (Amsterdam, the Netherlands) with the same primers as used for PCR.

\section{DNA sequence-based analyses}

Raw sequence data were processed with Geneious v. 5.6.7 (http://www.geneious.com, Kearse et al. 2012) and Sequencher v. 5.1 (Gene Codes Corporation, Ann Arbor, USA). For various sequence format conversion and alignment viewing, Mesquite v. 3.6 (build 917) (Maddison and Maddison 2018) and AliView v. 1.19 (Larsson 2014) were used. For phylogenetic data import and processing within $\mathrm{R}$, the following packages were used: "ape" (Paradis et al. 2004), "forcats" (Wickham 2019), "gdata" (Warnes et al. 2017), "geiger" (Harmon et al. 2008), "Hmisc" (Harrell Jr et al. 2019, and with contributions from Charles Dupont, many others 2019), "pals" (Wright 2018) and "treeio" (Yu 2019).

In this study, the following numbers of new nc ITS rDNA sequences were generated: 21 sequences for $S$. perlongisporum, three for $S$. cochleum and three for 
S. longisporum. For the nc $28 \mathrm{~S}$ rDNA, the numbers of sequences generated for these same species were 19, 3 and 2, respectively. The newly generated DNA sequences were submitted to GenBank (Benson et al. 2018). Additional six ITS and four $28 \mathrm{~S}$ sequences of S. perlongisporum and two ITS and three 28S sequences of $S$. longisporum available in GenBank (e.g. Volobuev 2016) and UNITE database (Nilsson et al. 2018) were used in our analyses after the corresponding herbarium specimens were examined (Table 1).

To relate the DNA sequences of $S$. perlongisporum, $S$. cochleum and S. longisporum to the rest of the genus Subulicystidium, we combined our data for these three species with the datasets of 57 ITS and 55 28S DNA sequences of other Subulicystidium species (Table 2). We used ITS and 28S DNA sequences from the holotype of S. oberwinkleri (KAS:L 1860 ) as an outgroup in all genus-level phylogenetic analyses.

Sequences from each locus, 92 of ITS region and 86 of $28 \mathrm{~S}$ region, were aligned in MAFFT v. 7 online (Katoh et al. 2017), with L-INS-i algorithm and other settings as default.

The small fragments of $18 \mathrm{~S}$ rDNA and 28S rDNA were automatically trimmed from the target ITS region with the ITSx software (Bengtsson-Palme et al. 2013) implemented in the PlutoF workbench (Abarenkov et al. 2010). The final ITS alignment had 659 nucleotide positions. The $28 \mathrm{~S}$ alignment was trimmed manually to produce sequences of the same length and with fewer (if any) gaps at both ends, leaving 911 positions in the final version. ITS and $28 \mathrm{~S}$ alignments were concatenated with the SequenceMatrix v. 1.8 (Vaidya et al. 2011) to produce a matrix with 100 rows and 1570 columns.

We performed phylogenetic reconstruction for Subulicystidium from concatenated ITS +28 S alignment using Bayesian and maximum likelihood analyses. For Bayesian inference of phylogeny, GTR+G+I evolutionary model was used in MrBayes 3.2.3 (Ronquist et al. 2012) run on CIPRES Science Gateway v. 3.3 (Miller et al. 2010; http://www.phylo. org). Two independent MCMC processes, each in 4 chains, were run. Ten million trees were generated; the sample frequency was set to 1000 and burn-in fraction to 0.25 . For 15,002 sampled trees (burn-in fraction excluded), a majorityrule consensus tree was computed with branch supports representing the relative frequencies of bipartitions (posterior probabilities, PP). This analysis was finished with the standard deviation of split frequencies of 0.0088 (equals average) and was characterized for branch and node parameters by the potential scale reduction factor between 0.999 and 1.003. The median of the log-likelihood for the sampled trees from two MCMC runs equalled $-11,344.25$ and the pooled effective sample size was 4924.1347 . The plot of the generation versus the log-likelihood values of the sampled trees was inspected with Tracer v. 1.6 (Rambaut 2014) to confirm the stationarity of the tree samplings.

Maximum likelihood analysis of concatenated ITS $+28 \mathrm{~S}$ alignment was performed with PhyML v. 3.0 (Guindon et al.
2010) after automated model selection with SMS v. 1.8.1, both run online (Lemoine et al. 2019, https://ngphylogeny. fr). Evolutionary model comparison was performed under Bayesian information criterion and resulted in selecting $\mathrm{TN} 93+\mathrm{G}+\mathrm{I}$ as the best-fitting model. BioNJ was used as a starting tree. The algorithm to explore the space of tree topologies was subtree pruning and regrafting (SPR). For branch support estimation, an approximate likelihood ratio test was requested that relies on a nonparametric, ShimodairaHasegawa-like procedure (SH-like aLRT, Guindon et al. 2010).

To visualize results for the genus-level concatenated ITS+ 28S dataset, the consensus tree from Bayesian analysis was plotted with both posterior probabilities from Bayesian analysis and SH-like aLRT support values from PhyML. For this, we used R script of Ordynets which is based on the R code from Crane (2013).

In the most abundant species, S. perlongisporum, we analyzed also the intraspecific genetic diversity. We produced a species-level ITS alignment with 27 sequences that after trimming with ITSx was 554 positions long. We calculated pairwise genetic distances between these ITS sequences using "pairDistPlot" function of "adegenet" $\mathrm{R}$ package (Jombart 2008) setting the arguments as follows: model = "raw", pairwise.deletion = TRUE (i.e. with deleting the sites with missing data in a pairwise way). Phylogenetic inference for this dataset was performed in PhyML v. 3.0 online with settings identical to those in the analysis of concatenated genuslevel dataset but with HKY85+G as the best model. The result was visualized with the R packages "ggtree" (Yu et al. 2017), "ggstance" (Henry et al. 2019) and "ggplot2" (Wickham 2009).

The multiple sequence alignments, details of phylogenetic analyses and trees were deposited in TreeBASE (Piel et al. 2009) under submission ID S24881. The R code for the DNA-based analyses and visualizations is available on GitHub (https://github.com/ordynets/subLongSpored).

\section{Results}

\section{Phylogenetic analyses}

The genus-level phylogenetic analyses based on the ITS $+28 \mathrm{~S}$ dataset showed that each of the species Subulicystidium cochleum, S. longisporum and S. perlongisporum is monophyletic (Fig. 1). The three species were not closely related to each other. $S$. cochleum (branch support $\mathrm{PP}=1$, aLRT $=$ 0.92 ) was placed as a sister species to $S$. acerosum on a highly supported branch $(\mathrm{PP}=1$, aLRT $=1) . S$. longisporum $(\mathrm{PP}=1$, aLRT $=0.95$ ) was nested in the clade dominated by numerous sequences of $S$. meridense and $S$. brachysporum $(\mathrm{PP}=0.94$, aLRT $=0.87) . S$. perlongisporum $(\mathrm{PP}=1$, aLRT $=0.98)$ was 
Table 1 DNA sequences of Subulicystidium perlongisporum, S. longisporum and S. cochleum with voucher specimen data and publication source. Abbreviation "na" means our failure to generate DNA sequence of a particular region

\begin{tabular}{|c|c|c|c|c|c|c|}
\hline \multirow[t]{2}{*}{ Species } & \multirow[t]{2}{*}{ Locality } & \multirow[t]{2}{*}{ Collector(s) } & \multirow[t]{2}{*}{$\begin{array}{l}\text { Voucher } \\
\text { specimens }\end{array}$} & \multicolumn{2}{|c|}{$\begin{array}{l}\text { GenBank/UNITE } \\
\text { accession numbers }\end{array}$} & \multirow[t]{2}{*}{ Source } \\
\hline & & & & ITS & $28 \mathrm{~S}$ & \\
\hline S. cochleum & Jamaica: Middlesex & K.-H. Larsson & GB: KHL 10517 & MN207035 & MN207023 & This study \\
\hline S. cochleum & Costa Rica: Alajuela & K.-H. Larsson & GB: KHL 11200 & MN207036 & MN207024 & This study \\
\hline S. cochleum & Madagascar: Anosy & K.-H. Larsson & O:F: KHL 14355 & MN207034 & MN207026 & This study \\
\hline S. longisporum & Italy: Sicily & A. Saitta & TU 124391 & UDB028356 & UDB028356 & Saitta (unpublished) \\
\hline S. longisporum & Sweden: Skåne & K.-H. Larsson & GB: KHL 14229 & MH000601 & MH000601 & Larsson (unpublished) \\
\hline S. longisporum & Ukraine: Zakarpatska & A. Ordynets & CWU 6737 & MN207038 & MN207016 & This study \\
\hline S. longisporum & Taiwan: Nantou & $\begin{array}{l}\text { G. Langer; E. Langer; } \\
\text { C.-J. Chen }\end{array}$ & KAS: GEL 3550 & MN207037 & AJ406423 & $\begin{array}{l}\text { This study and Langer } \\
\text { (2001), respectively }\end{array}$ \\
\hline S. longisporum & Germany: Hesse & A. Ordynets & $\begin{array}{l}\text { KAS: Ordynets } \\
00146\end{array}$ & MN207039 & MN207032 & This study \\
\hline $\begin{array}{l}\text { S. perlongisporum } \\
\text { (holotype) }\end{array}$ & Réunion: Saint-Benoît & J. Boidin & LY 11631 & MN207054 & MN207030 & This study \\
\hline S. perlongisporum & Brazil: Paraiba & K.-H. Larsson & O:F: KHL 16062 & МH000600 & MH000600 & This study \\
\hline S. perlongisporum & Brazil: Saõ Paulo, Cananeia & $\begin{array}{l}\text { D. Pegler; K. Hjortstam; } \\
\text { L. Ryvarden }\end{array}$ & O:F: LR 24826 & MN207042 & MN207029 & This study \\
\hline S. perlongisporum & Brazil: Saõ Paulo, Saõ Paulo & $\begin{array}{l}\text { D. Pegler; K. Hjortstam; } \\
\text { L. Ryvarden }\end{array}$ & GB: Hjm 16,340 & na & MN207017 & This study \\
\hline S. perlongisporum & Brazil: Saõ Paulo, Saõ Paulo & $\begin{array}{l}\text { D. Pegler; K. Hjortstam; } \\
\text { L. Ryvarden }\end{array}$ & GB: $\operatorname{Hjm} 16,465$ & MN207053 & MN207018 & This study \\
\hline S. perlongisporum & Cuba: Villa Clara & S. Kõljalg; U. Kõljalg & TU 108264 & UDB016775 & UDB016775 & Kõljalg (unpublished) \\
\hline S. perlongisporum & $\begin{array}{l}\text { Dominican Republic: } \\
\text { Provincia La Altagracia }\end{array}$ & K.-H. Larsson & GB: KHL 9926 & MN207041 & MN207027 & This study \\
\hline S. perlongisporum & $\begin{array}{l}\text { Dominican Republic: } \\
\text { Provincia La Romana }\end{array}$ & K.-H. Larsson & GB: KHL 9943 & MN207051 & MN207028 & This study \\
\hline S. perlongisporum & Estonia: Tartu & K. Ilves & TU 132022 & KI022V & na & Ilves (unpublished) \\
\hline S. perlongisporum & Germany: Hesse & A. Ordynets; M. Theiss & $\begin{array}{l}\text { KAS: Ordynets } \\
00158\end{array}$ & MN207056 & MN207033 & This study \\
\hline S. perlongisporum & Jamaica: Cornwall County & K.-H. Larsson & GB: KHL 10671 & MN207040 & na & This study \\
\hline S. perlongisporum & Madagascar: Ambotantihely & B. Buyck & $\begin{array}{l}\text { PC 0125118: } \\
\text { Buyck 001899 }\end{array}$ & MN207052 & MN207015 & This study \\
\hline S. perlongisporum & Madagascar: Ihorombe & K.-H. Larsson & O:F: KHL 14305 & MN207044 & MN207025 & This study \\
\hline S. perlongisporum & Italy: Sicily & A. Saitta & TU 124387 & UDB028354 & UDB028355 & Saitta (unpublished) \\
\hline S. perlongisporum & Italy: Sicily & A. Saitta & TU 124388 & UDB028355 & UDB028355 & Saitta (unpublished) \\
\hline S. perlongisporum & Réunion: Saint-Pierre & E. Langer & KAS: L 0103 & MN207058 & na & This study \\
\hline S. perlongisporum & Réunion: Saint-Benoît & E. Langer; E. Hennen & KAS: GEL 5217a & MN207043 & AJ406422 & $\begin{array}{l}\text { This study and Langer } \\
\text { (2001), respectively }\end{array}$ \\
\hline S. perlongisporum & Réunion: Saint-Paul & $\begin{array}{l}\text { G. Langer; E. Langer; E. } \\
\text { Hennen }\end{array}$ & KAS: GEL 4815 & MN207055 & na & This study \\
\hline S. perlongisporum & Réunion: Saint-Pierre & M. Striegel & KAS: L $1726 b$ & MN207045 & MN207022 & This study \\
\hline S. perlongisporum & Réunion: Saint-Pierre & J. Boidin & LY 12824 & MN207046 & MN207031 & This study \\
\hline S. perlongisporum & Russia: Kaluga & S. Volobuev & LE 302156 & KP268489 & MN217402 & Volobuev 2016 \\
\hline S. perlongisporum & Russia: Bryansk & S. Volobuev & LE 314099 & MN218448 & MN217406 & This study \\
\hline S. perlongisporum & Russia: Chuvash Republic & S. Bolshakov & LE 315315 & MN218449 & MN217535 & This study \\
\hline S. perlongisporum & Spain: Gipuzkoa & J.M. Riezu & $\begin{array}{c}\text { ARAN:Fungi } \\
3033195\end{array}$ & MN207050 & MN207014 & This study \\
\hline S. perlongisporum & Spain: Gipuzkoa & J.M. Riezu & $\begin{array}{l}\text { ARAN:Fungi } \\
4160\end{array}$ & MN207057 & na & This study \\
\hline S. perlongisporum & Taiwan: Chiayi & $\begin{array}{l}\text { G. Langer; E. Langer; } \\
\text { C.-J. Chen }\end{array}$ & KAS: GEL 3681 & MN207049 & MN207021 & This study \\
\hline S. perlongisporum & Taiwan: Miaoli & $\begin{array}{l}\text { G. Langer; E. Langer; } \\
\text { C.-J. Chen }\end{array}$ & KAS: GEL 3388 & MN207047 & MN207019 & This study \\
\hline S. perlongisporum & Taiwan: Miaoli & $\begin{array}{l}\text { G. Langer; E. Langer; } \\
\text { C.-J. Chen }\end{array}$ & KAS: GEL 3392 & MN207048 & MN207020 & This study \\
\hline
\end{tabular}

most closely related to $S$. robustius and $S$. rarocrystallinum (occupying the next more basal node) and to $S$. boidinii, S. harpagum, S. parvisporum and S. tropicum and to the specimen of $S$. obtusisporum from Jamaica (occupying the next highest node).
Concatenated ITS+28S DNA sequences from S. perlongisporum were grouped into two clades of unequal size (Fig. 1). The larger clade included the holotype (LY 11631) and sequences of various geographic origin (Paleotropics, Neotropics and temperate Europe) strongly 
Table 2 DNA sequences of Subulicystidium species besides S. perlongisporum, S. longisporum and S. cochleum used in this study with information on voucher specimens and publication source. Abbreviation "na" means sequence is not available

\begin{tabular}{|c|c|c|c|c|c|c|}
\hline \multirow[t]{2}{*}{ Species } & \multirow[t]{2}{*}{ Locality } & \multirow[t]{2}{*}{ Voucher specimen } & \multirow[t]{2}{*}{ Collector(s) } & \multicolumn{2}{|c|}{$\begin{array}{l}\text { GenBank/UNITE } \\
\text { accession numbers }\end{array}$} & \multirow[t]{2}{*}{ Source } \\
\hline & & & & ITS & $28 \mathrm{~S}$ & \\
\hline $\begin{array}{l}\text { Subulicystidium acerosum } \\
\text { (holotype) }\end{array}$ & China: Guizhou & BJFC 022303 & S.H. He & MK204539 & MK204543 & Liu et al. (2019) \\
\hline S. boidinii (holotype) & $\begin{array}{l}\text { Reunion: } \\
\text { Saint-Benoît }\end{array}$ & KAS: L 1584a & M. Striegel & MH041527 & na & $\begin{array}{l}\text { Ordynets et al. } \\
\text { (2018) }\end{array}$ \\
\hline S. boidinii & $\begin{array}{l}\text { Costa Rica: } \\
\text { Puntarenas }\end{array}$ & GB: KHL 12830 & K.-H. Larsson & MH041537 & MH041570 & $\begin{array}{l}\text { Ordynets et al. } \\
\text { (2018) }\end{array}$ \\
\hline S. brachysporum & Argentina: Misiones & O:F: 506782 & L. Ryvarden & MH041518 & MH041572 & $\begin{array}{l}\text { Ordynets et al. } \\
\text { (2018) }\end{array}$ \\
\hline S. brachysporum & Brazil: Paraiba & O:F: KHL 16100 & K.-H. Larsson & MH000599 & MH000599 & $\begin{array}{l}\text { Ordynets et al. } \\
\quad(2018)\end{array}$ \\
\hline S. brachysporum & Brazil: Rondonia & O:F: KHL 15352 & K.-H. Larsson & MH041553 & MH041576 & $\begin{array}{l}\text { Ordynets et al. } \\
\quad(2018)\end{array}$ \\
\hline S. brachysporum & Brazil: Saõ Paulo & GB: Hjm 16,573 & K. Hjortstam & MH041545 & MH041596 & $\begin{array}{l}\text { Ordynets et al. } \\
\text { (2018) }\end{array}$ \\
\hline S. brachysporum & $\begin{array}{l}\text { Colombia: } \\
\text { Magdalena }\end{array}$ & O:F: 918493 & L. Ryvarden & MH041522 & MH041605 & $\begin{array}{l}\text { Ordynets et al. } \\
\quad(2018)\end{array}$ \\
\hline S. brachysporum & Costa Rica: Alajuela & GB: KHL 11216 & K.-H. Larsson & MH041517 & MH041580 & $\begin{array}{l}\text { Ordynets et al. } \\
\quad(2018)\end{array}$ \\
\hline S. brachysporum & Jamaica: Cornwall & GB: KHL 10763 & K.-H. Larsson & MH041546 & MH041598 & $\begin{array}{l}\text { Ordynets et al. } \\
\quad(2018)\end{array}$ \\
\hline S. brachysporum & Jamaica: Middlesex & GB: KHL 10566 & K.-H. Larsson & na & MH041599 & $\begin{array}{l}\text { Ordynets et al. } \\
\quad(2018)\end{array}$ \\
\hline S. brachysporum & Madagascar: Anosy & O:F: KHL 14537 & K.-H. Larsson & MH041552 & MH041573 & $\begin{array}{l}\text { Ordynets et al. } \\
\quad(2018)\end{array}$ \\
\hline S. brachysporum & Puerto Rico: Isabela & GB: KHL 9544 & K.-H. Larsson & MH041555 & MH041560 & $\begin{array}{l}\text { Ordynets et al. } \\
\text { (2018) }\end{array}$ \\
\hline S. brachysporum & $\begin{array}{l}\text { Puerto Rico: } \\
\text { Luquillo }\end{array}$ & GB: KHL 10406 & K.-H. Larsson & MH041543 & MH041600 & $\begin{array}{l}\text { Ordynets et al. } \\
\qquad(2018)\end{array}$ \\
\hline S. brachysporum & $\begin{array}{l}\text { Puerto Rico: } \\
\text { Luquillo }\end{array}$ & GB: KHL 10411 & K.-H. Larsson & MH041549 & MH041601 & $\begin{array}{l}\text { Ordynets et al. } \\
\quad(2018)\end{array}$ \\
\hline S. brachysporum & $\begin{array}{l}\text { Réunion: } \\
\text { Saint-Pierre }\end{array}$ & KAS: L 0134 & E. Langer & MH041541 & MH041593 & $\begin{array}{l}\text { Ordynets et al. } \\
\quad(2018)\end{array}$ \\
\hline S. brachysporum & $\begin{array}{l}\text { Réunion: } \\
\text { Saint-Benoît }\end{array}$ & KAS: L 1584b & M. Striegel & MH041544 & MH041610 & $\begin{array}{l}\text { Ordynets et al. } \\
\text { (2018) }\end{array}$ \\
\hline S. brachysporum & $\begin{array}{l}\text { Réunion: } \\
\text { Saint-Pierre }\end{array}$ & KAS: L 1147 & J. Riebesehl; M. Schroth & MH041542 & MH041594 & $\begin{array}{l}\text { Ordynets et al. } \\
\text { (2018) }\end{array}$ \\
\hline S. brachysporum & $\begin{array}{l}\text { Réunion: } \\
\text { Saint-Pierre }\end{array}$ & KAS: L 1498 & M. Striegel & MH041526 & na & $\begin{array}{l}\text { Ordynets et al. } \\
\text { (2018) }\end{array}$ \\
\hline S. brachysporum & $\begin{array}{l}\text { Réunion: } \\
\text { Saint-Pierre }\end{array}$ & KAS: L 1795 & M. Striegel & MH041525 & MH041579 & $\begin{array}{l}\text { Ordynets et al. } \\
\quad(2018)\end{array}$ \\
\hline S. brachysporum & $\begin{array}{l}\text { Réunion: } \\
\text { Saint-Pierre }\end{array}$ & LY 12293 & G. Gilles & MH041550 & MH041571 & $\begin{array}{l}\text { Ordynets et al. } \\
\quad(2018)\end{array}$ \\
\hline S. brachysporum & $\begin{array}{l}\text { Réunion: } \\
\text { Saint-Pierre }\end{array}$ & LY 12772 & G. Gilles & na & MH041595 & $\begin{array}{l}\text { Ordynets et al. } \\
\text { (2018) }\end{array}$ \\
\hline S. brachysporum & Brazil: Rondonia & O:F: KHL 15318 & K.-H. Larsson & MH041557 & MH041577 & $\begin{array}{l}\text { Ordynets et al. } \\
\quad(2018)\end{array}$ \\
\hline S. brachysporum & Brazil: Rondonia & O:F: KHL 15327 & K.-H. Larsson & MH041539 & MH041603 & $\begin{array}{l}\text { Ordynets et al. } \\
\quad(2018)\end{array}$ \\
\hline S. brachysporum & Brazil: Saõ Paulo & O:F: LR 24170 & $\begin{array}{l}\text { D. Pegler; K. Hjortstam; L. } \\
\text { Ryvarden }\end{array}$ & MH041556 & na & $\begin{array}{l}\text { Ordynets et al. } \\
\text { (2018) }\end{array}$ \\
\hline S. brachysporum & Reunion: Saint-Paul & LY 11378 & J. Boidin & na & MH041574 & $\begin{array}{l}\text { Ordynets et al. } \\
\quad(2018)\end{array}$ \\
\hline S. fusisporum (holotype) & $\begin{array}{l}\text { Puerto Rico: Rio } \\
\text { Grande }\end{array}$ & GB: KHL 10360 & K.-H. Larsson & MH041535 & MH041567 & $\begin{array}{l}\text { Ordynets et al. } \\
\text { (2018) }\end{array}$ \\
\hline S. fusisporum & $\begin{array}{l}\text { Costa Rica: } \\
\text { Puntarenas }\end{array}$ & GB: KHL 12761 & K.-H. Larsson & MH041536 & MH041568 & $\begin{array}{l}\text { Ordynets et al. } \\
\quad(2018)\end{array}$ \\
\hline S. fusisporum & $\begin{array}{l}\text { Puerto Rico: Rio } \\
\text { Grande }\end{array}$ & GB: KHL 9093 & K.-H. Larsson & MH041534 & na & $\begin{array}{l}\text { Ordynets et al. } \\
\text { (2018) }\end{array}$ \\
\hline $\begin{array}{l}\text { S. grandisporum } \\
\text { (holotype) }\end{array}$ & Costa Rica: Cartago & O:F: 506781 & L. Ryvarden & MH041547 & MH041592 & $\begin{array}{l}\text { Ordynets et al. } \\
\text { (2018) }\end{array}$ \\
\hline S. harpagum (holotype) & $\begin{array}{l}\text { Réunion: } \\
\text { Saint-Pierre }\end{array}$ & KAS: L 1726a & M. Striegel & MH041532 & MH041588 & $\begin{array}{l}\text { Ordynets et al. } \\
\text { (2018) }\end{array}$ \\
\hline S. harpagum & $\begin{array}{l}\text { Colombia: } \\
\text { Magdalena }\end{array}$ & O:F: LR 15736 & L. Ryvarden & MH041531 & MH041586 & $\begin{array}{l}\text { Ordynets et al. } \\
\text { (2018) }\end{array}$ \\
\hline
\end{tabular}


Table 2 (continued)

\begin{tabular}{|c|c|c|c|c|c|c|}
\hline \multirow[t]{2}{*}{ Species } & \multirow[t]{2}{*}{ Locality } & \multirow[t]{2}{*}{ Voucher specimen } & \multirow[t]{2}{*}{ Collector(s) } & \multicolumn{2}{|c|}{$\begin{array}{l}\text { GenBank/UNITE } \\
\text { accession numbers }\end{array}$} & \multirow[t]{2}{*}{ Source } \\
\hline & & & & ITS & $28 \mathrm{~S}$ & \\
\hline S. harpagum & Jamaica: Cornwall & GB: KHL 10733 & K.-H. Larsson & MH041520 & MH041563 & $\begin{array}{l}\text { Ordynets et al. } \\
\text { (2018) }\end{array}$ \\
\hline S. harpagum & $\begin{array}{l}\text { Réunion: } \\
\text { Saint-Benoît }\end{array}$ & KAS: L 0244 & E. Langer & MH041533 & MH041609 & $\begin{array}{l}\text { Ordynets et al. } \\
\text { (2018) }\end{array}$ \\
\hline S. inornatum (holotype) & $\begin{array}{l}\text { Puerto Rico: Rio } \\
\text { Grande }\end{array}$ & GB: KHL 10444 & K.-H. Larsson & MH041558 & MH041569 & $\begin{array}{l}\text { Ordynets et al. } \\
\text { (2018) }\end{array}$ \\
\hline S. meridense & Brazil: Rondonia & O:F: KHL 15322 & K.-H. Larsson & MH041540 & MH041602 & $\begin{array}{l}\text { Ordynets et al. } \\
\text { (2018) }\end{array}$ \\
\hline S. meridense & Brazil: Saõ Paulo & GB: Hjm 16,400 & $\begin{array}{l}\text { D. Pegler; K. Hjortstam; L. } \\
\text { Ryvarden }\end{array}$ & MH041538 & MH041604 & $\begin{array}{l}\text { Ordynets et al. } \\
\text { (2018) }\end{array}$ \\
\hline S. meridense & $\begin{array}{l}\text { Costa Rica: } \\
\text { Guanacaste }\end{array}$ & GB: KHL 11355 & K.-H. Larsson & na & MH041583 & $\begin{array}{l}\text { Ordynets et al. } \\
\text { (2018) }\end{array}$ \\
\hline S. meridense & $\begin{array}{l}\text { Costa Rica: } \\
\text { Guanacaste }\end{array}$ & GB: KHL 11365 & K.-H. Larsson & MH041523 & MH041584 & $\begin{array}{l}\text { Ordynets et al. } \\
\quad(2018)\end{array}$ \\
\hline S. meridense & $\begin{array}{l}\text { Réunion: } \\
\text { Saint-Benoît }\end{array}$ & LY 12816 & G. Gilles & na & MH041597 & $\begin{array}{l}\text { Ordynets et al. } \\
\text { (2018) }\end{array}$ \\
\hline S. meridense & Taiwan: Nantou & KAS: GEL 3520 & $\begin{array}{l}\text { E. Langer; G. Langer; C.-J. } \\
\text { Chen }\end{array}$ & MH041548 & na & $\begin{array}{l}\text { Ordynets et al. } \\
\text { (2018) }\end{array}$ \\
\hline S. meridense & Argentina: Misiones & O:F: LR 19581 & L. Ryvarden & MH041551 & MH041578 & $\begin{array}{l}\text { Ordynets et al. } \\
\quad(2018)\end{array}$ \\
\hline S. meridense & Brazil: Rondonia & O:F: KHL 15325 & K.-H. Larsson & na & MH041585 & $\begin{array}{l}\text { Ordynets et al. } \\
\text { (2018) }\end{array}$ \\
\hline S. meridense & $\begin{array}{l}\text { Colombia: } \\
\text { Magdalena }\end{array}$ & O:F: 918846 & L. Ryvarden & MH041554 & MH041575 & $\begin{array}{l}\text { Ordynets et al. } \\
\text { (2018) }\end{array}$ \\
\hline S. meridense & $\begin{array}{l}\text { Puerto Rico: Cerro } \\
\text { Alto }\end{array}$ & GB: KHL 9561 & K.-H. Larsson & MH041524 & MH041581 & $\begin{array}{l}\text { Ordynets et al. } \\
\text { (2018) }\end{array}$ \\
\hline S. meridense & $\begin{array}{l}\text { Puerto Rico: } \\
\text { Luquillo }\end{array}$ & GB: KHL 10397 & K.-H. Larsson & MH041519 & MH041582 & $\begin{array}{l}\text { Ordynets et al. } \\
\text { (2018) }\end{array}$ \\
\hline S. nikau & $\begin{array}{l}\text { Réunion: } \\
\text { Saint-Pierre }\end{array}$ & KAS: L 1296 & J. Riebesehl; M. Schroth & MH041513 & MH041565 & $\begin{array}{l}\text { Ordynets et al. } \\
\text { (2018) }\end{array}$ \\
\hline S. oberwinkleri (holotype) & $\begin{array}{l}\text { Réunion: } \\
\text { Saint-Pierre }\end{array}$ & KAS: L 1860 & J. Riebesehl & MH041511 & MH041562 & $\begin{array}{l}\text { Ordynets et al. } \\
\quad(2018)\end{array}$ \\
\hline S. obtusisporum & Germany: Hesse & $\begin{array}{l}\text { FR: Piepenbrink \& } \\
\quad \text { Lotz-Winter W213-3-I }\end{array}$ & O. Koukol & MH041521 & MH041566 & $\begin{array}{l}\text { Ordynets et al. } \\
\text { (2018) }\end{array}$ \\
\hline S. obtusisporum & Jamaica: Cornwall & GB: KHL 10622 & K.-H. Larsson & MH041559 & MH041606 & $\begin{array}{l}\text { Ordynets et al. } \\
\text { (2018) }\end{array}$ \\
\hline S. parvisporum (holotype) & $\begin{array}{l}\text { Reunion: } \\
\text { Saint-Pierre }\end{array}$ & KAS: L 0140 & E. Langer & MH041529 & MH041590 & $\begin{array}{l}\text { Ordynets et al. } \\
\quad(2018)\end{array}$ \\
\hline S. parvisporum & $\begin{array}{l}\text { Réunion: } \\
\text { Saint-Benoît }\end{array}$ & KAS: L 1226 & J. Riebesehl & MH041528 & MH041587 & $\begin{array}{l}\text { Ordynets et al. } \\
\text { (2018) }\end{array}$ \\
\hline S. parvisporum & $\begin{array}{l}\text { Réunion: } \\
\text { Saint-Pierre }\end{array}$ & KAS: GEL 5032 & E. Langer; E. Hennen & MH041530 & MH041591 & $\begin{array}{l}\text { Ordynets et al. } \\
\quad(2018)\end{array}$ \\
\hline S. parvisporum & $\begin{array}{l}\text { Réunion: } \\
\text { Saint-Pierre }\end{array}$ & LY 12750 & G. Gilles & na & MH041589 & $\begin{array}{l}\text { Ordynets et al. } \\
\text { (2018) }\end{array}$ \\
\hline $\begin{array}{l}\text { S. rarocrystallinum } \\
\text { (holotype) }\end{array}$ & $\begin{array}{l}\text { Colombia: } \\
\text { Cundinamarcha }\end{array}$ & O:F: 918488 & L. Ryvarden & MH041512 & MH041564 & $\begin{array}{l}\text { Ordynets et al. } \\
\quad(2018)\end{array}$ \\
\hline S. robustius (holotype) & Jamaica: Cornwall & GB: KHL 10813 & K.-H. Larsson & MH041514 & MH041608 & $\begin{array}{l}\text { Ordynets et al. } \\
\text { (2018) }\end{array}$ \\
\hline S. robustius & Jamaica: Cornwall & GB: KHL 10780 & K.-H. Larsson & AY463468 & AY586714 & $\begin{array}{l}\text { Larsson } \\
\quad \text { (unpublished) }\end{array}$ \\
\hline S. robustius & $\begin{array}{l}\text { Puerto Rico: } \\
\text { Luquillo }\end{array}$ & GB: KHL 10039 & K.-H. Larsson & MH041515 & na & $\begin{array}{l}\text { Ordynets et al. } \\
\quad(2018)\end{array}$ \\
\hline S. robustius & $\begin{array}{l}\text { Puerto Rico: Rio } \\
\text { Grande }\end{array}$ & GB: KHL 10272 & K.-H. Larsson & MH041516 & MH041607 & $\begin{array}{l}\text { Ordynets et al. } \\
\text { (2018) }\end{array}$ \\
\hline S. tedersooi (holotype) & Vietnam: Ninh Bình & TU 110894 & L. Tedersoo & UDB014161 & na & $\begin{array}{l}\text { Tedersoo } \\
\quad \text { (unpublished) }\end{array}$ \\
\hline S. tedersooi & Vietnam: Ninh Bình & TU 110895 & L. Tedersoo & UDB014162 & na & $\begin{array}{l}\text { Tedersoo } \\
\quad \text { (unpublished) }\end{array}$ \\
\hline S. tropicum (holotype) & China: Hainan & BJFC 022470 & S.H. He & MK204531 & MK204544 & Liu et al. (2019) \\
\hline S. tropicum & China: Hainan & BJFC 022083 & S.H. He & MK204530 & MK204542 & Liu et al. (2019) \\
\hline S. tropicum & $\begin{array}{l}\text { Papua New Guinea: } \\
\text { Morobe }\end{array}$ & TU 110416 & L. Tedersoo & UDB013052 & UDB013052 & $\begin{array}{l}\text { Tedersoo } \\
\quad \text { (unpublished) }\end{array}$ \\
\hline
\end{tabular}


Subulicystidium species

acerosum

boidinii

cochleum

fusisporum

harpagum

inornatum

longisporum

nikau

oberwinkleri

obtusisporum

parvisporum

perlongisporum

rarocrystallinum

robustius

tedersooi

tropicum

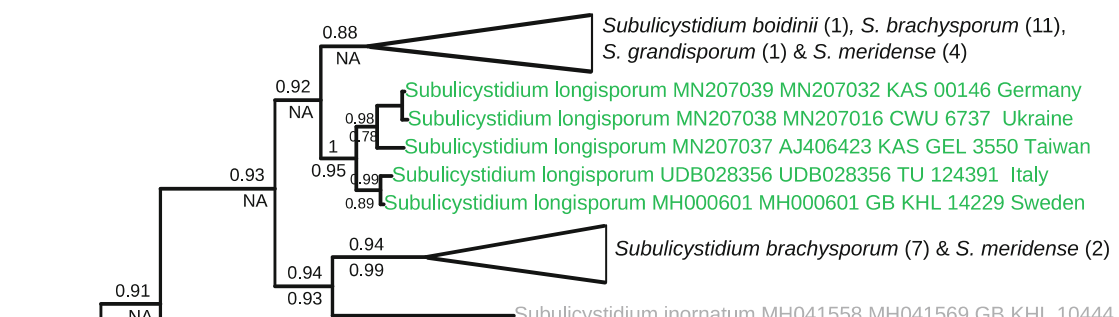

Subulicystidium fusisporum MH041534 GB KHL 9093 Puerto Rico

Subulicystidium fusisporum MH041535 MH041567 GB KHL 10360 Puerto Rico

0.99 Lubulicystidium fusisporum MH041536 MH041568 GB KHL 12761 Costa Rica

0.97 1 Subulicystidium tedersooi UDB014162 TU 110895 Vietnam

0.93 Subulicystidium tedersooi UDB014161 TU 110894 Vietnam
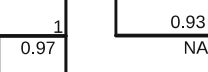

0.93 Subulicystidium brachysporum (5), S. harpagum (1),

S. meridense (5) \& S. obtusisporum (1)

0.63 -Subulicystidium cochleum MN207034 MN207026 O:F KHL 14355 Madagascar 1 Subulicystidium cochleum MN207036 MN207024 GB KHL 11200 Costa Rica

10.92 Lubulicystidium cochleum MN207035 MN207023 GB KHL 10517 Jamaica Subulicystidium acerosum MK204539 MK204543 BJFC 022303 He 3804 China

0.95 Subulicystidium parvisporum MH041589 LY 12750 Réunion

\begin{tabular}{ccc}
1 & 98 & 1 \\
\hline Subulicystidium parvisporum MH041530 MH041591 KAS GEL 5032 Réunion
\end{tabular}

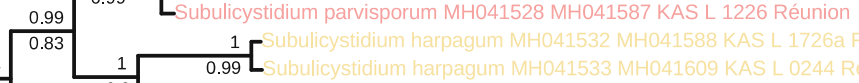

0.94

0.87

-Subulicystidium boidinii MH041527 KAS L 1584a Réunion

$\begin{array}{llll} & 1 & 0.69 & \text { Subulicystidium tropicum UDB013052 UDB013052 TU } 110416 \text { Papua New Guinea }\end{array}$

Subulicystidium tropicum MK204530 MK204542 BJFC 022083 He 3583 China

$0.96 \longleftarrow$ Subulicystidium obtusisporum MH041559 MH041606 G

Subulicystidium perlongisporum MN207046 MN207031 LY 12824 Réunion

0.99 Subulicystidium perlongisporum MN207044 MN207025 O:F KHL 14305 Madagascar

0.92 Subulicystidium perlongisporum MN207043 AJ406422 KAS GEL 5217a Réunion

0.92 Subulicystidium perlongisporum KI022V TU 132022 Estonia

0.94 Subulicystidium perlongisporum MN207045 MN207022 KAS L 1726b Réunion

Subulicystidium perlongisporum MN207047 MN207019 KAS GEL 3388 Taiwan

- Subulicystidium perlongisporum MN218448 MN217406 LE 314099 Russia

LSubulicystidium perlongisporum MN207050 MN207014 ARAN:Fungi 3033195 Spain

-Subulicystidium perlongisporum MN218449 MN217535 LE 315315 Russia

0.96 L Subulicystidium perlongisporum KP268489 MN217402 LE 302156 Russia

97 Lubulicystidium perlongisporum MN207048 MN207020 KAS GEL 3392 Taiwan

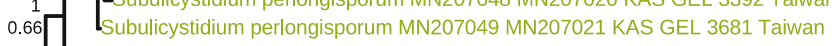

0.81 Subulicystidium perlongisporum MN207042 MN207029 O:F LR 24826 Brazil

4 Subulicystidium perlongisporum MN207051 MN207028 GB KHL 9943 Dominican Republic

Subulicystidium perlongisporum MN207041 MN207027 GB KHL 9926 Dominican Republic

0.54 Subulicystidium perlongisporum MH000600 MH000600 O:F KHL 16062 Brazil

0.54 Subulicystidium perlongisporum MN207053 MN207018 GB Him 16465 Brazil

Subulicystidium perlongisporum MN207017 GB Hjm 16340 Brazil

Subulicystidium perlongisporum MN207054 MN207030 LY 11631 Réunion

-Subulicystidium perlongisporum MN207040 GB KHL 10671 Jamaica

- Subulicystidium perlongisporum MN207055 KAS GEL 4815 Réunion

0.98 Subulicystidium perlongisporum MN207052 MN207015 PC Buyck 001899 Madagascar

1
0.98
Subulicystidium perlongisporum MN207052 MN207015 PC Buyck 001899 Madagascar

Root $\begin{array}{lll}0.96 \\ \text { NA }\end{array}$

Subulicystidium oberwinkleri MH041511 MH041562 KAS L 1860 Réunion

Fig. 1 Phylogenetic relationship of Subulicystidium based on concatenated ITS $+28 \mathrm{~S}$ nc rDNA alignment. $50 \%$ majority-rule consensus tree from Bayesian analysis is shown, with posterior probabilities above the branches and supports from approximated likelihood ratio test from the maximum likelihood estimation below the branches, both in the range from 0 to 1 . NA means the absence of branch support. Tips of the tree include GenBank/UNITE accession numbers for the ITS region followed by $28 \mathrm{~S}$ region, voucher specimen and country of collection. Tree tips are coloured according to the species name. Scale bar shows the number of substitutions per site 
a

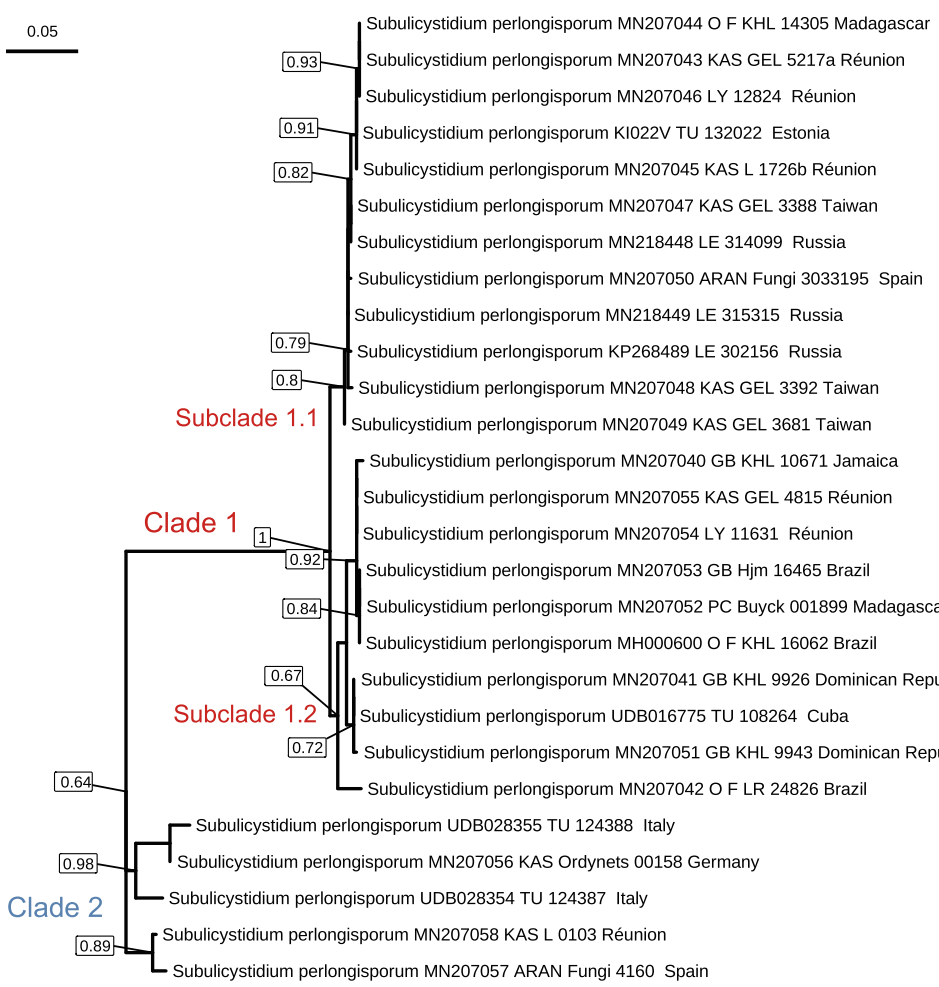

b Multiple sequence alignment of ITS nrDNA

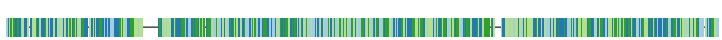

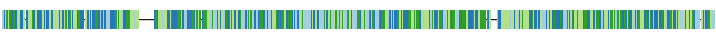

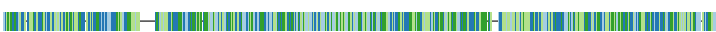

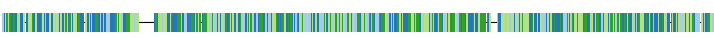

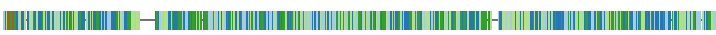

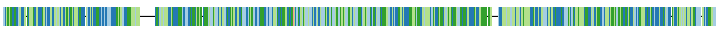

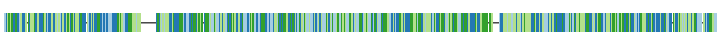

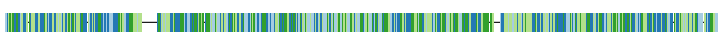

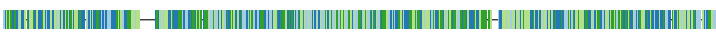

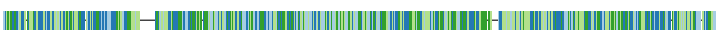
-

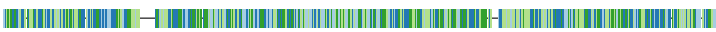
| -

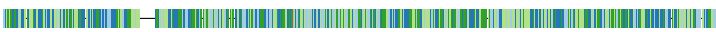

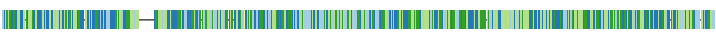

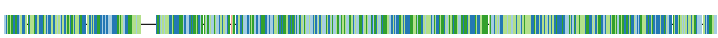

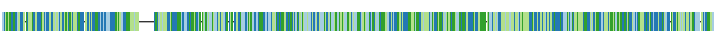

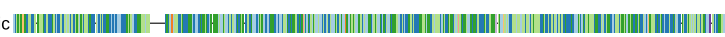

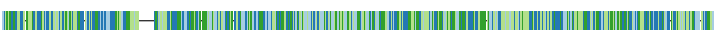
|

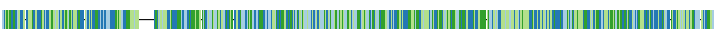

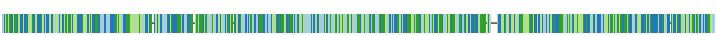

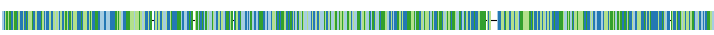

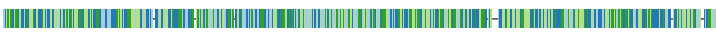

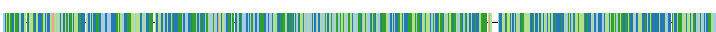

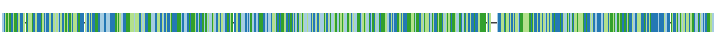

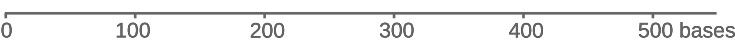
from approximated likelihood ratio tests. Scale bar (a): number of substitutions per site, (b) DNA sequence length in bases

Fig. 2 Relationship of ITS nrDNA sequences of Subulicystidium perlongisporum (a) and corresponding multiple sequence alignment (b). Maximum likelihood phylogenetic tree includes branch supports

intermixed. The smaller clade contained two specimens from temperate Europe, two from the Mediterranean region in

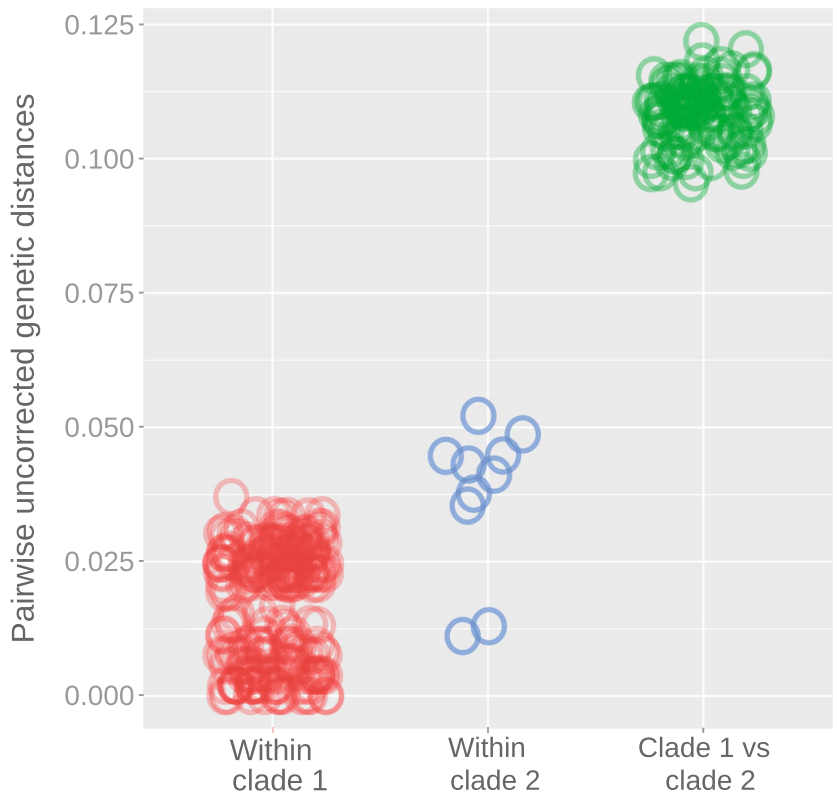

Fig. 3 Genetic distances within and between phylogenetic clades $1(n=$ $22)$ and $2(n=5)$ of Subulicystidium perlongisporum based on ITS nc rDNA sequences

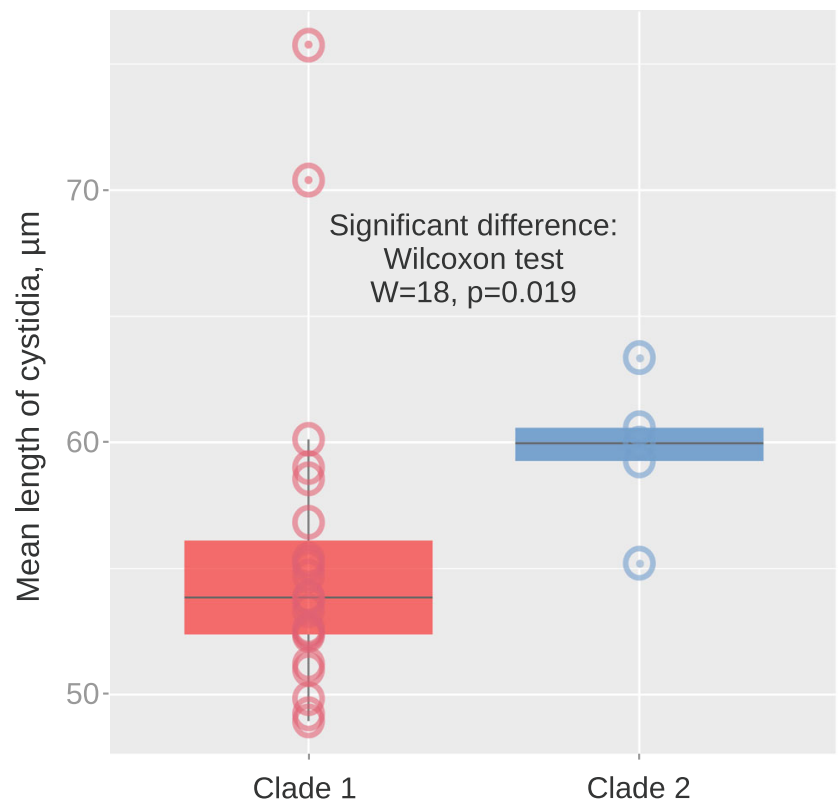

Fig. 4 Variation in length of cystidia within clades $1(n=23)$ and $2(n=$ 5) of Subulicystidium perlongisporum. Boxes display 25 th and 75 th quantiles of the data range and contain a median (50\% quantile). Whiskers represent 1.5 times the interquartile range and circles with a dot in the centre are the outliers 


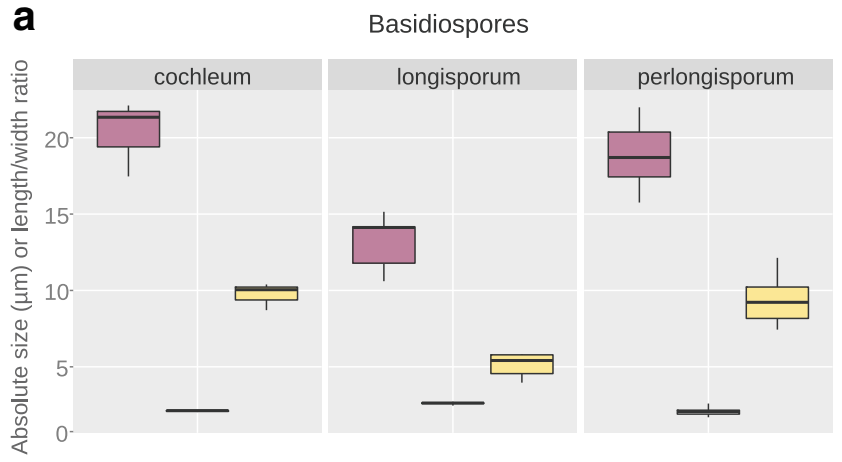

b

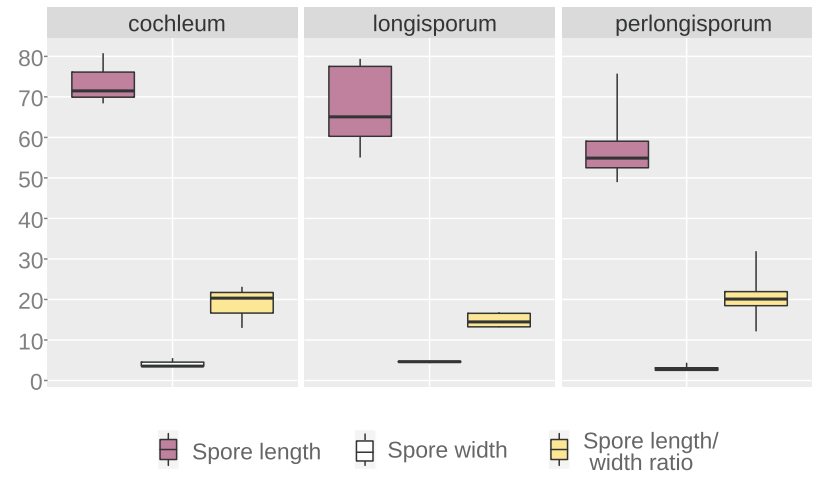

Fig. 5 Mean size range of spores (a) and cystidia (b) in the long-spored species of Subulicystidium. Boxes (with median inside) delimit the range between 25 and $75 \%$ data quantiles (i.e. mean measurements per specimen), while higher or lower values are covered by the whiskers

Europe and one specimen from the Southern Hemisphere (La Réunion).

Within the larger clade of $S$. perlongisporum, further labelled as clade $1($ aLRT $=1)$, two subclades on short basal branches were distinguishable (Fig. 2a). Subclade 1.1 $(\mathrm{aLRT}=0.8)$ included DNA sequences merely from the Eastern Hemisphere while subclade $1.2(\mathrm{aLRT}=0.67)$ was dominated by DNA sequences from the Western Hemisphere. The sequences from La Réunion and Madagascar were found in both subclades.

\section{Genetic and morphological diversity within S. perlongisporum}

Between the ITS rDNA sequences of $S$. perlongisporum, there were signatures in the multiple sequence alignment that allowed to differentiate clade 2 from clade 1 . The most striking feature of clade 2 was the insertion at positions 107-118 (Fig. 2b). Additionally, there was an insertion at positions 381385 in sequences that formed subclade 1.1 in the ITS tree (Fig. 2a).

Pairwise genetic distances were lowest between members of clade 1 (maximum 0.037 , median 0.021 ; Fig. 3 ) and slightly higher between members of clade 2 (maximum 0.052 , median 0.042). The distances between the members of clades 1 and 2 were always distinctly higher (maximum 0.122 , median 0.109).

Between the clades 1 and 2 of $S$. perlongisporum, there were no differences in the mean length, width and length-towidth ratio of spores (Supplementary fig. S4.1a and table S4.2). The mean length of cystidia per specimen was significantly higher in clade 2 compared with that in clade 1 (Wilcoxon $W=18, p=0.019$, Fig. 4). There were no differences in the mean width and length-to-width ratio of cystidia between clades 1 and 2 .

\section{Morphological differences between long-spored Subulicystidium species}

Morphological comparison based only on specimens for which DNA sequences were obtained showed that $S$. cochleum, S. longisporum and S. perlongisporum differed in basidiospore length (Fig. 5a). Basidiospore width and length-to-width ratio distinguished $S$. longisporum from $S$. perlongisporum and $S$. cochleum but did not separate the two latter species. S. perlongisporum had shorter and narrower cystidia than the two other species (Fig. 5b).

\section{Discussion}

In this study, we assessed the range of molecular (nc rDNA) and morphological variation in the long-spored species of Subulicystidium: S. cochleum, S. longisporum and S. perlongisporum. We found that each of these species was monophyletic. However, none of them was sister to any of the other. For S. cochleum and S. perlongisporum, we confirmed a transoceanic distribution pattern.

We included the holotype of $S$. perlongisporum in our study (LY11631) and successfully obtained ITS and 28S DNA sequences from this 35 -year-old specimen. We generated first DNA sequence data for the species $S$. cochleum. We successfully sequenced collections made in Costa Rica, Jamaica and Madagascar, but failed to obtain sequences from those made in Réunion and Zimbabwe. We provided additional morphometric and genetic data for S. longisporum. Furthermore, phylogenetic analyses allowed us to re-identify the specimen from Papua New Guinea (TU110416) as S. tropicum (previous identification: S. brachysporum). The new identification was added to the specimen and DNA sequence records in the PlutoF platform (https://plutof.ut.ee/\#/ specimen/view/651339; Abarenkov et al. 2010).

With the support of molecular data, we demonstrated a rather broad intraspecific variation in studied Subulicystidium species, especially in the length of spores and cystidia. Following the recommendations of Parmasto 
et al. (1987), we provided more accurate morphological data for S. perlongisporum, S. cochleum and S. longisporum by separating intra-individual, intraspecific and interspecific size variation. Our data showed that basidiospores of $S$. cochleum and $S$. perlongisporum can be considerably shorter than stated in the protologues of these species (Punugu et al. 1980; Boidin and Gilles 1988). Previous authors also faced this problem and apparently attributed more importance to the values of spore width and length-to-width ratio for identification (Boidin and Gilles 1988; Duhem and Michel 2001). We confirm that spore length is more variable than the spore width or length-to-width ratio in the studied species of Subulicystidium.

Despite the similarity in the shape and size of spores, the three long-spored Subulicystidium species were not closely related. Therefore, the spore shape can be considered a homoplasic character in this genus. On the other hand, we recovered a sister relationship for $S$. cochleum and $S$. acerosum. They share cystidia that are sheathed by needle-like crystals in the middle part. This crystal arrangement is different from most species in Subulicystidium that have rectangular crystals arranged in longitudinal rows. In $S$. oberwinkleri, a peculiar cystidium ornamentation (crystal plates) correlates with an isolated phylogenetic position. The cystidial encrustation deserves more attention in further studies on Subulicystidium.

We found that $S$. perlongisporum includes two sympatric lineages. Morphologically these lineages differed slightly, but significantly, in the mean length of cystidia (longer in clade 2) but not in other characters of cystidia and spores. The genetic distance between ITS nrDNA sequences from these two lineages was as high as are usually the distances between separate species within the same fungal genus, i.e. well over $3 \%$ (Schoch et al. 2012; Kõljalg et al. 2013).

Clades 1 and 2 of $S$. perlongisporum differed strongly in the number of available specimens, viz. 22 versus 5. The holotype of S. perlongisporum from La Réunion Island (LY 11631) was recovered in clade 1 . The DNA sequences within clade 1 were more similar and were connected by shorter branches on the phylogenetic tree than the members of clade 2 . We see a need for additional data for clade 2 , in order to test whether it represents more than one cryptic lineage, and in order to confirm with a more balanced sampling whether the observed difference in the length of cystidia compared to clade 1 is real. Until then, we are reluctant to introduce any new species name.

Using nc ITS rDNA data, other authors showed that a single corticioid species may represent numerous phylogenetic lineages. Allopatric speciation was found within Hyphoderma setigerum and Xylodon raduloides species complexes (Nilsson et al. 2003; Fernández-López et al. 2019). In contrast, the clades of Peniophorella praetermissa species complex contained specimens of very distant geographic origin suggesting sympatric speciation (Hallenberg et al. 2007). Morphological differences between the members of the clades in the above-mentioned species complexes were often missing. Our finding for
$S$. perlongisporum is congruent with the pattern for $P$. praetermissa, although the former includes only two clades while the latter has eight. It remains a challenge to explain why allopatric speciation prevails in some species complexes while genetically deviating populations may occur sympatrically in others, even when all share a saprotrophic lifestyle and live in strongly decayed wood.

Struck et al. (2018) consolidated the concept of cryptic species and stated that crypsis may represent a substantial fraction of biodiversity. They emphasized the need for a quantitative assessment of morphological disparity versus genetic divergence and comparing them with those for non-cryptic taxa. However, methods for quantitative assessment of morphological variation should become more standardized. Our protocols for morphometric analysis used for Subulicystidium (Ordynets et al. 2018; Ordynets and Denecke 2018) can be applied to all other fungi. We hope these protocols will enhance the reproducibility of the morphometric analysis in mycology and facilitate the correlation of morphometric data with genomic-scale DNA data.

Acknowledgements We would like to thank the curators of herbaria and mycologists who provided loan specimens for our study: Ibai Olariaga (ARAN), Markus Scholler (KR), Mélanie Thiébaut (LY), Irja Saar (TU), Cornelia Dilger-Endrulat and Franz Oberwinkler (TUB). Ulrike Frieling and Sylvia Heinemann (University of Kassel) and Rasmus Puusepp (University of Tartu) are deeply acknowledged for the assistance with the molecular laboratory work. We thank the reviewers and editors for their comments that helped to improve the manuscript.

Author contributions A. Ordynets conceived the idea. K.-H. Larsson, E. Langer, A. Saitta, S. Volobuev, S. Bolshakov, B. Buyck and E. Yurchenko collected and identified fungal specimens. R. Liebisch, A. Ordynets, A. Saitta, D. Scherf, L. Lysenko, S. Volobuev and S. Bolshakov obtained morphometric data. R. Liebisch, A. Saitta, D. Scherf, L. Lysenko, S. Volobuev, S. Bolshakov and K.-H. Larsson performed molecular lab work and generated DNA sequences. A. Ordynets, R. Liebisch and D. Scherf analyzed the data. A. Ordynets wrote the first version of the manuscript and all authors read, contributed to and agreed on the final version.

Funding information Open Access funding provided by Projekt DEAL. The work of A. Ordynets and E. Langer was partly funded by the LOEWE excellence initiative of the state of Hesse (Germany) within the framework of the Cluster for Integrative Fungal Research (IPF). K.-H. Larsson received support from SIU, Norwegian Centre for International Cooperation in Education (projects CAPES-SIU-2013/10057 and CAPES-SIU-2015/ 10004). The work of S. Volobuev and S. Bolshakov was carried out within the framework of the institutional research project AAAA-A19119020890079-6 using equipment of The Core Facilities Center "Cell and Molecular Technologies in Plant Science" at the Komarov Botanical Institute RAS (St.-Petersburg, Russia).

Open Access This article is licensed under a Creative Commons Attribution 4.0 International License, which permits use, sharing, adaptation, distribution and reproduction in any medium or format, as long as you give appropriate credit to the original author(s) and the 
source, provide a link to the Creative Commons licence, and indicate if changes were made. The images or other third party material in this article are included in the article's Creative Commons licence, unless indicated otherwise in a credit line to the material. If material is not included in the article's Creative Commons licence and your intended use is not permitted by statutory regulation or exceeds the permitted use, you will need to obtain permission directly from the copyright holder. To view a copy of this licence, visit http://creativecommons.org/licenses/by/4.0/.

\section{References}

Abarenkov K, Tedersoo L, Nilsson RH et al (2010) PlutoF-a web based workbench for ecological and taxonomic research, with an online implementation for fungal its sequences. Evol Bioinforma 6: EBO.S6271. https://doi.org/10.4137/EBO.S6271

Bengtsson-Palme J, Ryberg M, Hartmann M et al (2013) Improved software detection and extraction of ITS1 and ITS2 from ribosomal ITS sequences of fungi and other eukaryotes for analysis of environmental sequencing data. Methods Ecol Evol 4:914-919. https://doi.org/ 10.1111/2041-210X.12073

Benson DA, Cavanaugh M, Clark K, Karsch-Mizrachi I, Ostell J, Pruitt KD, Sayers EW (2018) GenBank. Nucleic Acids Res 46(D1):D41D47. https://doi.org/10.1093/nar/gkx1094

Boidin J, Gilles G (1988) Basidiomycètes aphyllophorales de l'Ile de la Réunion. XII: Le genre Subulicystidium Parmasto Bull Trimest la Société Mycol Fr 104:191-198

Crane S (2013) labelNodeSupport. R function. https://github.com/ s a mu e $1 \mathrm{crane} / 1 \mathrm{ab}$ e $1-\mathrm{n}$ od e - s u p port/b lob/ cf4671dc01eab90e9c7d06aae29fabae2df0f834/labelNodeSupport. r. Accessed 15 Aug 2019

Duhem B, Michel H (2001) Contribution à la connaissance du genre Subulicystidium Parmasto 1968 (Basidiomycota, Xenasmatales). Cryptogam Mycol 22:163-173. https://doi.org/10.1016/S01811584(01)01067-3

Fernández-López J, Telleria MT, Dueñas M et al (2019) Addressing the diversity of Xylodon raduloides complex through integrative taxonomy. IMA Fungus 10:9. https://doi.org/10.1186/s43008-019-0010$\mathrm{x}$

Gardes M, Bruns TD (1993) ITS primers with enhanced specificity for basidiomycetes, application to the identification of mycorrihiza and rusts. Mol Ecol 2:113-118. https://doi.org/10.1111/J.1365-294x. 1993.Tb00005.X

Gorjón SP, Greslebin AG, Rajchenberg M (2012) Subulicystidium curvisporum sp. nov. (Hymenochaetales, Basidiomycota) from the Patagonian Andes. Mycotaxon 118:47-52. https://doi.org/10.5248/ 118.47

Guindon S, Dufayard JF, Lefort V et al (2010) New algorithms and methods to estimate maximum-likelihood phylogenies: assessing the performance of PhyML 3.0. Syst Biol 59:307-321. https://doi. org/10.1093/sysbio/syq010

Hallenberg N, Nilsson RH, Antonelli A et al (2007) The Peniophorella praetermissa species complex (Basidiomycota). Mycol Res 111: 1366-1376. https://doi.org/10.1016/j.mycres.2007.10.001

Harmon LJ, Weir JT, Brock CD et al (2008) GEIGER: investigating evolutionary radiations. Bioinformatics 24:129-131. https://doi. org/10.1093/bioinformatics/btm538

Harrell Jr FE, with contributions from Charles Dupont, many others. (2019) Hmisc: Harrell miscellaneous. R package version 4.20.https://cran.r-project.org/package=Hmisc

Henry L, Wickham H, Chang W (2019) ggstance: horizontal "ggplot2" components. R package version 0.3.2. https://cran.r-project.org/ package $=$ ggstance

Hopple JS, Vilgalys R (1999) Phylogenetic relationships in the mushroom genus coprinus and dark-spored allies based on sequence data from the nuclear gene coding for the large ribosomal subunit rna: divergent domains, outgroups, and monophyly. Mol Phylogenet Evol 13:1-19. https://doi.org/10.1006/mpev.1999.0634

Index Fungorum (2019) Index Fungorum. http://www.indexfungorum. org. Accessed 9 Oct 2019.

Izumitsu K, Hatoh K, Sumita T et al (2012) Rapid and simple preparation of mushroom DNA directly from colonies and fruiting bodies for PCR. Mycoscience 53:396-401. https://doi.org/10.1007/s10267012-0182-3

Jombart T (2008) adegenet: a R package for the multivariate analysis of genetic markers. Bioinformatics 24:1403-1405. https://oi.org/10. 1093/bioinformatics/btn129

Katoh K, Rozewicki J, Yamada KD (2017) MAFFT online service: multiple sequence alignment, interactive sequence choice and visualization. Brief Bioinform. https://doi.org/10.1093/bib/bbx 108

Kearse M, Moir R, Wilson A et al (2012) Geneious Basic: an integrated and extendable desktop software platform for the organization and analysis of sequence data. Bioinformatics 28:1647-1649. https:// doi.org/10.1093/bioinformatics/bts199

Kõljalg U, Nilsson RH, Abarenkov K et al (2013) Towards a unified paradigm for sequence-based identification of fungi. Mol Ecol 22: 5271-5277. https://doi.org/10.1111/mec.12481

Langer E (2001) Phylogeny of non-gilled and gilled basidiomycetes: DNA sequence inference, ultrastructure and comparative morphology. Habilitationsschrift, Universität Tübingen, Tübingen

Larsson A (2014) AliView: a fast and lightweight alignment viewer and editor for large datasets. Bioinformatics 30:3276-3278. https://doi. org/10.1093/bioinformatics/btu531

Lemoine F, Correia D, Lefort V et al (2019) NGPhylogeny.fr: new generation phylogenetic services for non-specialists. Nucleic Acids Res 47:W260-W265. https://doi.org/10.1093/nar/gkz303

Liberta AE (1980) Notes on the genus Subulicystidium. Mycotaxon 10: 409-412

Liu S-L, Ma H-X, He S-H, Dai Y-C (2019) Four new corticioid species in Trechisporales (Basidiomycota) from East Asia and notes on phylogeny of the order. MycoKeys 48:97-113. https://doi.org/10.3897/ mycokeys.48.31956

Maddison WP, Maddison DR (2018) Mesquite: a modular system for evolutionary analysis. Version 3.6 (build 917). http://www. mesquiteproject.org

Martini E (2020) Crusts and jells. URL: https://www.aphyllo.net, access date: 26 Feb 2020.

Miller MA, Pfeiffer W, Schwartz T (2010) Creating the CIPRES Science Gateway for inference of large phylogenetic trees. In: 2010 Gateway Computing Environments Workshop (GCE). IEEE, pp. 1-8.

Nilsson RH, Hallenberg N, Nordén B et al (2003) Phylogeography of Hyphoderma setigerum (Basidiomycota) in the Northern Hemisphere. Mycol Res 107:645-652. https://doi.org/10.1017/ S0953756203007925

Nilsson RH, Larsson K-H, Taylor AFS et al (2018) The UNITE database for molecular identification of fungi: handling dark taxa and parallel taxonomic classifications. Nucleic Acids Res. https://doi.org/10. 1093/nar/gky1022

O'Donnell K (1992) Fusarium and its near relatives. The fungal holomorph: mitotic, meiotic and pleomorphic speciation in fungal systematics. CAB International, Wallingford, pp 225-233

Oberwinkler F (1977) Species and generic concepts in the Corticiaceae. In: The species concept in Hymenomycetes. Cramer, Vaduz, pp. 331-348.

Ordynets A (2018) Plotting phylogenetic tree with branch supports from two phylogenetic analyses. In: protocols.io. https://doi.org/10. 17504/protocols.io.n9fdh3n

Ordynets A, Denecke J (2018) Calculating and plotting size range of morphological structures. In: protocols.io. https://doi.org/10. 17504/protocols.io.n7tdhnn 
Ordynets A, Scherf D, Pansegrau F et al (2018) Short-spored Subulicystidium (Trechisporales, Basidiomycota): high morphological diversity and only partly clear species boundaries. MycoKeys 35:41-99. https://doi.org/10.3897/mycokeys.35.25678

Paradis E, Claude J, Strimmer K (2004) APE: analyses of phylogenetics and evolution in R language. Bioinformatics 20:289-290. https:// doi.org/10.1093/bioinformatics/btg412

Parmasto E, Parmasto I, Möls T (1987) Variation of basidiospores in the hymenomycetes and its significance to their taxonomy. J. Cramer, Berlin, Stuttgart

Patouillard NT (1894) Quelques espèces nouvelles de Champignons du nord de l'Afrique. J Bot 8:219-221

Piel W, Chan L, Dominus M, et al. (2009) TreeBASE v. 2: a database of phylogenetic knowledge. In: e-BioSphere 2009. London.

Punugu A, Dunn MT, Welden AL (1980) Peniophoroid fungi of the West Indies. Mycotaxon 10:428-454

R Core Team (2019) R: a language and environment for statistical computing. Version 3.5.3https://www.r-project.org/

Rambaut A (2014) FigTree, a graphical viewer of phylogenetic trees. Version 1.4.4. http://tree.bio.ed.ac.uk/software/figtree/

Ronquist F, Teslenko M, van der Mark P et al (2012) MrBayes 3.2: efficient Bayesian phylogenetic inference and model choice across a large model space. Syst Biol 61:539-542. https://doi.org/10.1093/ sysbio/sys029

Rüdigs J (2019) Makroaufmaßprogramm. URL: https://ruedig.de/tmp/ messprogramm.htm. Accessed 15 Aug 2019.

Schoch CL, Seifert KA, Huhndorf S et al (2012) Nuclear ribosomal internal transcribed spacer (ITS) region as a universal DNA barcode marker for Fungi. Proc Natl Acad Sci 109:6241-6246. https://doi. org/10.1073/pnas.1117018109

Struck TH, Feder JL, Bendiksby M et al (2018) Finding evolutionary processes hidden in cryptic species. Trends Ecol Evol 33:153-163. https://doi.org/10.1016/j.tree.2017.11.007

Tedersoo L, Jairus T, Horton BM et al (2008) Strong host preference of ectomycorrhizal fungi in a Tasmanian wet sclerophyll forest as revealed by DNA barcoding and taxon-specific primers. New Phytol 180:479-490. https://doi.org/10.1111/j.1469-8137.2008.02561.x

Vaidya G, Lohman DJ, Meier R (2011) SequenceMatrix: concatenation software for the fast assembly of multi-gene datasets with character set and codon information. Cladistics 27:171-180. https://doi.org/ 10.1111/j.1096-0031.2010.00329.x

Volobuev S (2016) Subulicystidium perlongisporum (Trechisporales, Basidiomycota) new to Russia, with notes on a molecular study of the species. Nov Hedwigia 102:531-537. https://doi.org/10.1127/ nova_hedwigia/2016/0329

Warnes GR, Bolker B, Gorjanc G, et al. (2017) gdata: various R programming tools for data manipulation. $\mathrm{R}$ package version 2.18.0. https:// cran.r-project.org/package $=$ gdata

White TJ, Bruns S, Lee S, Taylor J (1990) Amplification and direct sequencing of fungal ribosomal RNA genes for phylogenetics. In: Innis MA, Gelfand D, Sninsky JJ, White TJ (eds) PCR Protocols: a guide to methods and applications. Academic Press, New York, pp 315-322

Wickham H (2009) ggplot2: elegant graphics for data analysis. Springer, New York

Wickham H (2019) forcats: tools for working with categorical variables (factors). R package version 0.4 .0 . https://cran.r-project.org/ package $=$ forcats

Wickham H, François R, Henry L, Müller K (2019) dplyr: a grammar of data manipulation. $\mathrm{R}$ package version 0.8 .0 . https://cran.r-project. org $/$ package $=$ dplyr

Wilk J (2012) Smaff - "Statistische Messreihen-Auswertung für Fungi v3.1.”. Südwestdeutsche Pilzrundschau 48:49-56

Wright K (2018) pals: color palettes, colormaps, and tools to evaluate them. R package version 1.5. https://cran.r-project.org/package=pals

Yu G (2019) treeio: base classes and functions for phylogenetic tree input and output. R package version 1.6.2. https://guangchuangyu.github. io/software/treeio

Yu G, Smith DK, Zhu H et al (2017) ggtree: an R package for visualization and annotation of phylogenetic trees with their covariates and other associated data. Methods Ecol Evol 8:28-36. https://doi.org/ 10.1111/2041-210X.12628

Publisher's note Springer Nature remains neutral with regard to jurisdictional claims in published maps and institutional affiliations. 